\title{
COMPARISON OF INTRAVENOUS VERSUS INTR-ARTERIAL HEPARIN FOR THE PREVENTION OF RADIAL ARTERY OCCLUSION DURING TRANSRADIAL CORONARY ARTERY CATHETHERIZATION
}

\author{
Waqas Khalid, Mohsin Saif*, Aliya Halim, Anam Fatima Janjua, Kumail Abbas Khan, Amer Rauf, Zohair Aziz, \\ Sohail Aziz
}

\begin{abstract}
Armed Forces Institute of Cardiology/National Institute of Heart Disease (AFIC/NIHD)/National University of Medical Sciences (NUMS) Rawalpindi Pakistan, *Armed Forces Institute of Radiology \& Imaging/National University of Medical Sciences (NUMS) Rawalpindi Pakistan
\end{abstract}

\section{ABSTRACT}

Objective: To determine the relative efficacy of intravenous heparin as compared to intra-arterial heparin used during transradial coronary angiography for the prevention of radial artery occlusion.

Study Design: Comparative cross-sectional study.

Place and Duration of Study: Study was conducted at the Department of Cardiology, AFIC/NIHD Rawalpindi, Pakistan, from Jul 2019 to Dec 2019.

Methodology: A total number of 144 patients were considered for the study using the consecutive sampling technique who were undergoing diagnostic coronary angiography. Patients were divided into the intra-arterial group ( $\mathrm{n}=72$ ) who received $50 \mathrm{IU} / \mathrm{kg}$ of unfractionated heparin (maximal dose 5,000 U) intra-arterially, and an intravenous group $(n=72)$ received the similar dose through intravenous route. All patients were administered $100 \mathrm{mcg}$ of nitroglycerin to minimize radial artery spasm. Coronary Angiography was performedusing a $6 \mathrm{~F}$ introducer sheath and diagnostic catheters. Early radial artery occlusion (RAO) at 24 hours after the procedure was detected by performing the plethysmographic (reverse Barbeau's) and doppler USG evaluation. Chronic RAO was assessed 30 days after the procedure by performing the same tests. Data was collected through a predesigned proforma and analyzed using SPSS 23. A $p$-value of less than 0.05 was considered as significant.

Results: Early RAO was found in $4(5.6 \%)$ of the patients from the intra-arterial groupand $5(6.9 \%)$ of the intravenous group. The difference was found to be statistically insignificant ( $p$-value 0.731). Chronic RAO was observed in $3(4.4 \%)$ of the intra-arterial group as compared to $4(6 \%)$ of the intravenous group. This difference was also statistically insignificant ( $p$-value 0.683 ) for chronic RAO.

Conclusion: Intra-arterial and intravenous heparin administration providedsimilar efficacy to prevent RAO.

Keywords: Angiography, Heparin, Intra-arterial, Intravenous, Radial.

This is an Open Access article distributed under the terms of the Creative Commons Attribution License (http://creativecommons.org/licenses/by/4.0), which permits unrestricted use, distribution, and reproduction in any medium, provided the original work is properly cited.

\section{INTRODUCTION}

Trans radial access (TRA) has evolved to become the main access site around the world. It has proved to decreasethe mortality and adverse cardiac events especially in high-risk patient groups as compared to trans femoral access. It is due to decreased major bleeding and access site-related vascular problemsthrough transradial route. It also causes less patient discomfort. Moreover, TRA provides the advantage of early mobilization of patients andalso minimize scosts related to the procedure ${ }^{1,2}$. Therefore, TRA has been recommended asa Class IA indication by the Euro-

Correspondence: Dr Waqas Khalid, Department of Cardiology, AFIC/NIHD Rawalpindi Pakistan pean Society of Cardiology for the patients of acute coronary syndromes undergoing invasive coronary catherization ${ }^{3}$. However, TRA can be challenging and can have complications. TRA is technically more demanding and has a longer learning curve. Radial artery occlusion (RAO) is usually an asymptomatic complication of transradial procedures ${ }^{4}$ and is very well tolerated due to the dual blood supply of palmar arch. However, it prohibits the use of same radial artery for future procedures. RAO also disallows the benefits of radial access in high bleeding risk patients and radial artery cannot be utilized as a graft for the coronary artery bypass grafting (CABG). Incidence of $\mathrm{RAO}$ is variable andextends from $1 \%$ to $9 \%$. RAO is caused by a thrombotic process 
initiated from the termination of flow due to introduction of catheter in the radial artery lumen and it is intensified by additional spread of the process owing to the occlusive hold ${ }^{5}$. Incidence of RAO can be reduced by the use of heparin ${ }^{6}$ which is administered through intravenous route by some operators while others prefer the intra-arterial route for heparin administration. Although the protective effect of heparin on RAO was established initially through intravenous route administration, heparin is mostly given throughan intra-arterial routeas a part of the "radial cocktail" by most operators these days. It is sometimes hypothesized that intra-arterial heparin can be more advantage ousowing to the local effect. This study was designed to compare the efficacy of heparin in the prevention of RAO through intra-arterial versus intravenous route of administration.

\section{METHODOLOGY}

This comparative cross-sectional study was conducted at the Department of Cardiology, AFIC/NIHD Rawalpindi, Pakistan from July 2019 to December 2019. A total of 144 patients, aged 18 years or older, undergoing elective diagnostic coronary angiography, were considered for the study using the consecutive sampling technique. Patients were randomized into two equal groups. Intra-arterial group $(n=72)$ received 50 $\mathrm{IU} / \mathrm{kg}$ of unfractionated heparin (maximal dose $5,000 \mathrm{U}$ ) intra-arterially, whereas, the intravenous group $(n=72)$ received the equivalent dose intravenously. The operator had no information about the route of administration. All patients received $100 \mathrm{mcg}$ of nitroglycerin to minimize radial artery spasm. The modified Allen's test was performed prior to radial access. It was done by requesting patients to clench and hold their fistwhile radial and ulnar arteries were compressed simultaneously by the examiner. Blood flow to the hand was temporarily restricted by this manuvere which was evidenced by pale blanching of the skin. While the examiner released compression of the ulnar artery, the patient was then told to open their fist. The return of palmar colour to normal with in 7 seconds was considered as normal mo- dified Allen's test indicating adequate collateral circulation. Patients with abnormal modified Allen's test, the prior history of coronary artery bypass graft surgery and prior radial artery cannulation were excluded from the study. Angiography was performed using ${ }^{6}$ French diagnostic catheters. Early RAO at 24 hours and chronic RAO at 30 days after the procedure was detected by plethysmographic evaluation using reverse Barbeau's test. This test involved placing a pulse oximeter sensorover the index finger. Examiner compressed both the radial and ulnar arteriesto observe a loss of the plethysmographic signal. Next, the return of the plethysmographic signal was observed while theradial artery pressure was released which confirmed radial artery flow and patency. RAO was interpreted by the absence of the return of the plethysmographic signal. The pressure on the ulnarartery was then released to observe the return of the signal as a confirmation of appropriate functioning of the equipment. Doppler ultrasound evaluation was done to confirm all the cases of RAO and person doing the ultrasound assessment had no information about the route of heparin administration.

Data was entered and analyzed by IBM SPSS 23 after obtaining informed written consent for individual data and approval of Hospitals Scientific and Ethics Committee. Mean and standard deviation was calculated for quantitative variables like age and qualitative data were analyzed using the chi-square test and a $p$-value of less than 0.05 was considered significant.

\section{RESULTS}

The demographic variables are compared between the two groups in table-I. Intra-arterial group had early RAO (found at 24 hours of follow-up) in $4(5.6 \%)$ of the patients and intravenous group had early RAO in 5 (6.9\%) of patients. The difference was found to be statistically insignificant ( $p$-value 0.731). Chronic RAO (found at 30 days of follow-up) was found in $3(4.4 \%)$ of the intra-arterial group and in intravenous group, 4 $(6 \%)$ of patients had chronic RAO. This difference was also not statistically significant ( $p$-value 
0.683) (figure). Radial artery spasm was noticed in $5.6 \%$ of the intra-arterial group and $4.2 \%$ of the intravenous group. The difference was statistically insignificant ( $p$-value 0.698) (table-II).

Table-I: Clinical characteristics of patients (n=144).

\begin{tabular}{|c|c|}
\hline Parameters & Mean \pm SD / n (\%) \\
\hline Age & $57.82 \pm 9.309$ years \\
\hline \multicolumn{2}{|l|}{ Gender } \\
\hline Male & 88 (61.1) \\
\hline Female & 56 (38.9) \\
\hline Smoking & $25(17.4)$ \\
\hline Diabetes Mellitus & $52(36.1)$ \\
\hline Hypertension & $108(75.0)$ \\
\hline Dyslipidemia & $27(18.8)$ \\
\hline Family history & $20(13.9)$ \\
\hline
\end{tabular}

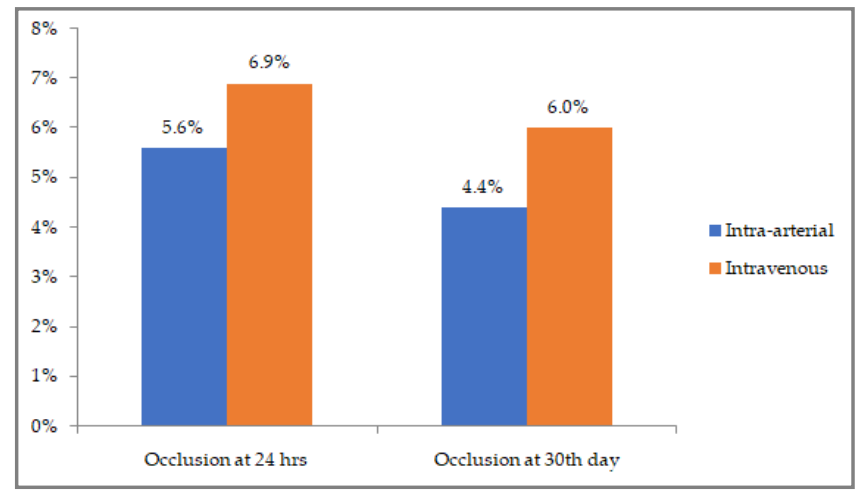

Figure: Incidence of the radial artery occlusion in intravenous and intra-arterial groups at 24 hours $(p=0.731)$ and 30 days $(p=0.683)$ after the procedure. sive hemostasis act as the central process in early RAO after TRA. A considerable fraction of these patients will develop chronic RAO. The pathogenesis of chronic RAO involves progressive intimal-medial thickening due to vascular smooth muscle proliferation and hyperplasia as a response to injury during TRA ${ }^{8,9}$. Therefore, careful precautionary measures are required in relation to various procedural and post-procedural factors involved in RAO. Procedure related parameters include recurring failed attempts of radial punctures, lack of aspirin pre-treatment, increased sheath-to-artery ratio and lack of periprocedural intravascular anticoagulation ${ }^{10,11-13}$. Post-procedural risk factors specifically include non patenthemostasis $5,14,15$ and prolonged time for hemostasis ${ }^{16-19}$. Anticoagulation during procedure is crucial to prevent RAO because thrombus formation is central factor leading to occlusion of radial artery. It is also apparent from the published literature that a major fraction of acutely occluded radial artery is found to be recanalized during the follow-up evaluation at one month after procedure ${ }^{4}$. This is most likely due to recanalization of the occlusive thrombus due to spontaneous fibrinolysis. The comparative dominance between fibrinolytic and thrombus organizational factorsdictates whether the chronic occlusion of radial artery develops or there is spontaneous recanalization. The possibility of recanalization is aug-

Table-II: Comparison of procedural factors between intra-arterial and intravenous groups.

\begin{tabular}{l|c|c|c}
\hline Variables & Intra-arterial & Intravenous & $p$-value \\
\hline Procedure success & $71(98.6 \%)$ & $72(100.0 \%)$ & 0.316 \\
\hline Radial artery spasm & $4(5.6 \%)$ & $3(4.2 \%)$ & 0.698 \\
\hline
\end{tabular}

\section{DISCUSSION}

Radial artery occlusion is the most frequent post-procedural complication of radial access which restricts the future use of theradial artery for invasive procedures and as a conduit in CABG. Hence, avoidance of RAO is of paramount clinical importance and should be of prime concern ${ }^{7}$. Acute arterial thrombosis which results from the collective effect of catheter-related endothelial and vessel injury, local hypercoagulable state, and decreased blood flow from compres- mented by creating a systemically anticoagulated state through the maintenance of heparinized condition which inhibits prothrombotic processes and shifts the balance towards spontaneous fibrinolysis. Alatest international survey has revealed that the most operators $(92.5 \%)$ administer unfractionated heparin (UFH) with considerable variation in dosage and administration route during diagnostic transradial coronary angiography ${ }^{20}$. The initial reports have also suggested that the efficacy of heparin in preventing RAO appears 
to be dose-dependent as increasing the dose from 2,000 $\mathrm{U}$ to $5,000 \mathrm{U}$ causes a significant additional decline in the incidence of $\mathrm{RAO}, 21$. Our results have revealed that intravenous heparin is equally effective to intra-arterial heparin in preventing RAO. Athough heparin is administered directly into the instrumented radial artery, the intra-arterial route does not provide any added advantage in preventing RAO. This has further validated the major role played by the systemically anticoagulated state in preventing $\mathrm{RAO}$, rather than the local effect by intra-arterial adm-inistration. Intravenous heparin administration might provide a minor advantage over intra-arterial administration due to the decreased burning sensation in the forearm as compared to the intra-arterial route. Data from research has also testified the additional efficacy of "patent hemostasis" in minimizing the incidence of RAO ${ }^{14}$. The efficacy of patent hemostasis has further signified the importance of maintaining blood flow in decreasing chronic occlusion by reducing the probability of occlusive thrombus formation at the access site.

\section{CONCLUSION}

Heparin plays an important role in preventing RAO after trans-radial access and can be administered by intravenous or intra-arterial route with equal efficacy. It is thus evident that maintenance of systemically anticoagulated is crucial in preventing RAO rather than local effect of intra-arterial administration.

\section{CONFLICT OF INTEREST}

This study has no conflict of interest to be declared by any author.

\section{REFERENCES}

1. Cooper CJ, El-Shiekh RA, Cohen DJ. Effect of transradial access on quality of life and cost of cardiac catheterization: A randomized comparison. Am Heart J 1999; 138(3Pt1): 430-36.

2. Mamas MA, Anderson SG, Ratib K,. Arterial access site utilization incardiogenic shock in the United Kingdom: is radial access feasible? Am Heart J 2014; 167(6): 900-08.

3. Ibanez B, James S, Agewall S. 2017 ESC Guidelines for the management of acute myocardial infarction in patients presenting with ST-segment elevation: the task force for the management of acute myocardial infarction in patients presenting with ST-segment elevation of the European Society of Cardiology (ESC). Eur Heart J 2018; 39(2): 119-77.
4. Stella PR, Kiemeneij F, Laarman GJ, Odekerken D, Slagboom T, vander Wieken R. Incidence and outcome of radial artery occlusion following transradial artery coronary angioplasty. Catheter Cardiovasc Diagn 1997; 40: 156-58.

5. Sanmartin M, Gomez M, Ramon J, Sadaba M, Martinez M, Baz J, et al. Interruption of blood flow during compression and radialartery occlusion after transradial catheterization. Catheter Cardiovasc Interv 2007; 70: 185-89.

6. Pancholy SB, Bertrand OF, Patel T. Comparison of a priori versus provisional heparin therapy on radial artery occlusion after transradial coronary angiography and patent hemostasis (from the PHARAOH study). Am J Cardiol 2012; 110(2): 173-76.

7. Mamas MA, Fraser DG, Ratib K,. Minimising radial injury: prevention is better than cure. Euro Intervention 2014; 10: 824-32.

8. Yonetsu T, Kakuta T, Lee T. Assessmentof acute injuries and chronic intimal thickening ofthe radial artery after transradial coronary interventionby optical coherence tomography. Eur Heart J 2010; 31: 1608-15.

9. Abdelaal E, Molin P, Plourde G. Successive transradial access for coronary procedures: experience of Quebec Heart-Lung Institute. Am Heart J 2013; 165: 325-31.

10. Aminian A, Saito S, Takahashi A. Comparisonof a new slender 6 Fr sheath with a standard $5 \mathrm{Fr}$ sheath for transradial coronary angiography and intervention: RAP and BEAT (Radial Artery Patency and Bleeding, Efficacy, Adverse even T), a ran-domized multicentre trial. Euro Interven 2017; 13: e549-56.

11. Dahm JB, Vogelgesang D, Hummel A. A randomized trial of 5 vs. 6 French transradial percutaneous coronary interventions. Catheter CardiovascInterv 2002; 57: 172-6.

12. Hahalis GN, Leopoulou M, Tsigkas G. Multicenter randomized evaluation of high versus standard heparin dose on incident radial arterial occlusion after transradial coronary angiography: the SPIRIT OF ARTEMIS study. J Am Coll Cardiol Intv 2018; 11: 2241-50.

13. Costa F, van Leeuwen MA, Daemen J. The Rotterdam Radial Access Research: ultrasound based radial artery evaluation for diagnostic and therapeutic coronary procedures. Circ Cardiovasc Interv 2016; 9: e003129.

14. Pancholy S, Coppola J, Patel T. Prevention of radial artery occlusion-patent hemostasis evaluation trial (PROPHET study): a randomized comparison of traditional versus patency documented hemostasis after transradial catheterization. Catheter Cardiovasc Interv 2008; 72: 335-40.

15. Cubero JM, Lombardo J. Radial compression guided by mean artery pressure versus standard compression with a pneumatic device (RACOMAP). Cath Cardiovas Inter 2009; 73: 467-72.

16. Pancholy SB, Patel TM. Effect of duration of hemostatic compression on radial artery occlusion after transradial access. Catheter Cardiovasc Interv 2012; 79: 78-81.

17. Dangoisse V, Guedès A, Chenu P. Usefulness of a gentle and short hemostasis using the transradial band device after transradial access for percutaneous coronary angiography and interventions to reduce the radial artery occlusion rate (from the prospective and randomized CRASOC I, II,and III studies). Am J Cardiol 2017; 120: 374-79.

18. Dharma S, Kedev S, Patel T. A novel approach to reduce radial artery occlusion after transradial catheterization: postprocedural / prehemostasis intra-arterial nitroglycerin. Catheter Cardiovasc Interv 2015; 85: 818-25.

19. Aminian A, Saito S, Takahashi A. Impact of sheath size and hemostasis time on radial artery patency after transradial coronary angiography and intervention in Japanese and nonJapanese patients: a sub-study from RAP and BEAT (radial 
artery patency and bleeding, efficacy, Adverse even T) randomized multicenter trial. Cath Cardiovasc Interv 2018; 92: 844-51.

20. Bossard M, Lavi S, Rao SV. Heparin use for diagnostic cardiac catheterization with a radial artery approach: an international survey of practice patterns. Cath Cardiovasc Interv 2018; 92:
854-59.

21. Lefevre T, Thebault B, Spaulding C, Funck F, Chaveau M, Guillard N, et al. Radial artery patency after percutaneous left radial artery approach for coronary angiography: the role of heparin. Eur Heart J 1995; 16: 293-97. 